\title{
Correction of torsion deformities in adolescents and adults with cerebral palsy, impact on gait parameters
}

\author{
O.I. Gatamov ${ }^{1}$, G.M. Chibirov', D.Yu. Borzunov ${ }^{1,2}$ T.I. Dolganova ${ }^{1}$, D.V. Dolganov ${ }^{1}$, D.A. Popkov ${ }^{1}$
}

${ }^{1}$ Russian Ilizarov Scientific Centre for Restorative Traumatology and Orthopaedics, Kurgan, Russian Federation,

${ }^{2}$ Tyumen State Medical University, Tyumen, Russian Federation

\begin{abstract}
Purpose To evaluate the changes in gait parameters in patients over 16 years old with cerebral palsy who underwent detorsion osteotomy in the lower extremities as part of multilevel interventions. Materials and methods This retrospective study evaluated functional treatment results of 32 adolescents and adult patients (average age, $23.4 \pm 6.5$ years). Included were patients with cerebral palsy, able to move independently and having clinically significant torsion deformities of the lower limb bones. Exclusion criteria were age younger than 16 years, as well as patients with stiff knee gait and crouch gait. All patients underwent multilevel single-event surgical interventions, including detorsion osteotomy. Gait analysis using the Edinburgh visual gait score was conducted before surgery, and 1.5-2 years after the interventions. Patients were divided into group 1 who had no previous surgical interventions, or had undergone the Strayer operation, and group 2 after surgical interventions such as lengthening of the Achilles tendon or fibromyotomy in the early age. Results Before the operation in group 1, the changes in the parameters corresponded to true equinus gait or jump gait in combination with internal rotation of the lower extremities. Correction of torsion deformities of the femurs improved the orientation of the knee joints. In the support phase, improvements were recorded for initial contact, heel lift, maximum dorsiflexion of the foot, rotation and obliquity of the pelvis. In the non-support phase of the cycle, clearance, maximum dorsiflexion of the foot, and peak flexion of the knee joint improved. Before the operation in group 2, the changes corresponded to true equinus gait in combination with the internal rotation of the knee joints in the support phase in five subjects. In the remaining patients, torsion was combined with the initial contact produced by the forefoot due to excessive bending of the knee joint at the terminal swing of the non- support phase, followed by late heel lift and insufficient knee joint straightening in the support phase. It can be explained by weakening of the triceps due to previous operations. Correction of the femur significantly improved the orientation of the knee joint. In the support phase of the cycle, improvements were in the initial contact, heel lift, maximum dorsiflexion of the foot, and pelvic rotation. Lengthening of the knee flexors enabled to improve the maximum extension of the knee joint in the support phase of the gait cycle in all patients. No improvement in trunk balance was found in either the first or second group in the long-term period. Differences were statistically significant by comparing the parameters between the groups before surgery according to the Mann-Whitney criterion showing better results in patients of group 1 . The result in the long-term period did not show statistically significant differences. Conclusion Correction of torsion deformities of the lower extremities in adolescents and adult patients with cerebral palsy as part of multilevel single-event interventions results in improvement in many gait parameters and the overall total score. During the follow-up period of 1.5-2 years after surgery, there was no improvement in the parameters of the trunk balance by walking. Patients who underwent early surgical interventions in childhood had worse walking parameters before surgery than the patients not operated previously.

Keywords: cerebral palsy, single-event multilevel orthopedic surgery, derotation osteotomy
\end{abstract}

\section{INTRODUCTION}

An internal rotation gait in patients with spastic cerebral palsy is a complex disorder of the motor function combining the torsion and dynamic components as well as lower limb joint contractures of varying severity $[1,2]$. These disorders cause lever arm dysfunctions in the support phase of the gait and are indications for correction of torsion deformities within a procedure of multilevel interventions [3-5], which assist in improving the overall motor activity and social integration of children and adults [6].

Correction of torsion deformities in adolescents and adults is peculiar due to high correlation between the anatomical parameters and the quantitative gait analysis [7], in contrast to pediatric patients. However, the rehabilitation period after interventions in adults takes a longer period than in children [8], which, possibly, reflects less opportunities for the adult population to achieve previous motor activity lost due to developed and long-standing orthopedic complications of cerebral palsy [2, 9].

The available literature describes interventions on tendons and muscles in patients with cerebral palsy in childhood, and the correction of torsion deformities in

@ Gatamov O.I., Chibirov G.M., Borzunov D.Yu., Dolganova T.I., Dolganov D.V., Popkov D.A. Correction of torsion deformities in adolescents and adults with cerebral palsy, impact on gait parameters. Genij Ortopedii, 2019, vol. 25, no 4, pp. 510-516. DOI 10.18019/1028-4427-2019-25-4-510-516. (In Russian) 
adulthood. However, the effects of torsion correction on gait parameters in adults, depending on the interventions on soft tissues previously performed or lack of such, as well as on the types of interventions have not been evaluated.
The purpose of this retrospective study was to evaluate the changes in gait parameters in patients with cerebral palsy older than 16 years who underwent detorsion osteotomy on the lower extremities as part of multilevel interventions.

\section{MATERIAL AND METHODS}

This retrospective study is evaluation of the functional treatment results of 32 patients ( 24 females, 8 males) who were over 16 years of age and had a natural closure of the lower limb growth zones by the time of the operation. The study included patients who were able to move independently, who suffered from spastic diplegia and had clinically significant torsion deformities of the lower limb bones, and namely, torsion of the femur and lower leg bones of $20^{\circ}$ or more (according to computed tomography performed on a Toshiba Aquilion-64 CT system, Japan; certificate No. FSZ 2007/00891 dated 12.24.2007). Of these, more than $80 \%$ were patients with internal torsion of the femurs and lower leg bones and about $20 \%$ with external torsion.

Exclusion criteria were age under 16 years, as well as stiff knee gait and crouch gait.

The average age was $23.4 \pm 6.49$ years (range, 16 to 37 years). Thirty patients had GMFCS level II and three had level III. Four patients underwent the Strayer surgery in the age over seven years. Fourteen patients underwent interventions in the early age: staged fibrotomy or fibromyotomy according to the Ulzibat "method" [10] or open lengthening of the Achilles tendon under the age of five years.

All patients underwent multilevel singleevent surgical interventions, including detorsion osteotomy. Sequential bilateral femoral osteotomy was performed in 20 patients, and eight had unilateral osteotomy but soft tissue interventions on both sides. Sequential bilateral osteotomies on the lower leg were performed in two patients, and two had unilateral osteotomy with simultaneous intervention on the soft tissues on both sides. A total of 54 operations were performed. On average, a single-event operation included 2.94 surgical elements. The elements of surgical interventions are presented in Table 1.

Table 1

Elements of surgical interventions

\begin{tabular}{|l|c|}
\hline \multicolumn{1}{|c|}{ Element } & Number \\
\hline $\begin{array}{l}\text { Lengthening of the medial group of knee } \\
\text { flexors, tenotomy m. gracilis }\end{array}$ & 32 \\
\hline Lengthening of abductors & 8 \\
\hline Aponeurotomy of m. gastrocnemius & 36 \\
\hline Shortening of tendon of m. tibialis post. & 4 \\
\hline Detorsion osteotomy of the femur & 48 \\
\hline Detorsion osteotomy of the tibia & 6 \\
\hline Achilles lengthening & 1 \\
\hline Hallux valgus correction & 10 \\
\hline Patella lowering & 6 \\
\hline Talonavicular arthrodesis & 4 \\
\hline Evans foot deformity correction & 4 \\
\hline Total & 159 \\
\hline
\end{tabular}

Gait analysis using the Edinburgh visual gait score was done before surgery, and 1.5-2 years after the intervention [11]. Patients in whom torsion deformity had to be corrected were divided into two groups. Group 1 patients did not have any history of surgical intervention prior to our treatment, or had only the Strayer surgery. Group 2 patients were after early surgical interventions (open lengthening of the Achilles tendon or fibromyotomy). All patients in whom detorsion was done in the tibia were included into one group, given their small number.

AtteStat 12.0.5 program was used for statistical data processing. Descriptive statistics included the mean and its standard deviation. Mann-Whitney test was used to determine the significance of differences in Edinburgh gait scores between the groups.

\section{RESULTS}

In the groups compared, the average values for each of the 17 parameters of the Edinburgh visual gait score are presented in Tables 2 and Table 3, and in Table 4 for the group of tibial torsion deformity correction. The kinematic parameters of gait significantly improved in the patients after the operations.
In group 1 before the operation, the changes in parameters corresponded to true equinus gait or jump gait combined with knee joint internal rotation in the support phase. At long term after the operation, the deviation from the normal values reduced by three times. Correction of femoral torsion significantly normalized 
the parameter of knee joint orientation in the support phase. Moreover, improvements were observed in the initial contact, heel lift, maximum ankle dorsiflexion, pelvic rotation and pelvic obliquity. In the non-support phase, the improvements were clearance, maximum dorsiflexion of the foot and peak knee flexion. There was almost no improvement in the trunk balance in the sagittal and frontal planes at long term.

Table 2

Average Edinburgh score in group 1, the patients of which did not have surgical interventions, or had aponeurotomies of $\mathrm{m}$. gastrocnemius in the age older than 7 years

\begin{tabular}{|l|c|c|}
\hline \multicolumn{1}{|c|}{ Parameter } & $\begin{array}{c}\text { Before } \\
\text { treatment }\end{array}$ & $\begin{array}{c}\text { Follow-up in } \\
1.5-2 \text { years }\end{array}$ \\
\hline Initial contact & 1.33 & 0.17 \\
\hline Heel lift & 0.94 & 0.5 \\
\hline Maximum ankle dorsiflexion & 1.06 & 0.06 \\
\hline Hind-foot varus/valgus & 0.28 & 0.22 \\
\hline Foot progression angle & 0.22 & 0.11 \\
\hline Knee progression angle & 1.44 & 0.28 \\
\hline Peak knee extension & 0.5 & 0.06 \\
\hline Peak hip extension & 0.39 & 0.28 \\
\hline Pelvic obliquity at Mid-Stance & 0.78 & 0.33 \\
\hline Pelvic rotation at Mid-Stance & 0.39 & 0.06 \\
\hline Trunk Peak Sagittal Position & 0.39 & 0.39 \\
\hline Trunk maximum lateral shift & 1.0 & 0.89 \\
\hline Clearance & 0.44 & 0.0 \\
\hline Maximum ankle dorsiflexion & 1.1 & 0.06 \\
\hline Peak knee flexion & 0.83 & 0.06 \\
\hline Knee terminal swing position & 0.22 & 0.17 \\
\hline Peak hip flexion & 0.22 & 0.22 \\
\hline Total & $23.1 \pm 10.7$ & $7.7 \pm 4.0 *$ \\
\hline
\end{tabular}

Table 3

Average Edinburgh scores in group 2, the patients of which underwent early surgical interventions before the age of five years

\begin{tabular}{|l|c|c|}
\hline \multicolumn{1}{|c|}{ Parameter } & $\begin{array}{c}\text { Before } \\
\text { treatment }\end{array}$ & $\begin{array}{c}\text { Follow-up in } \\
1.5-2 \text { years }\end{array}$ \\
\hline Initial contact & 1.4 & 0.67 \\
\hline Heel lift & 1.58 & 0.75 \\
\hline Maximum ankle dorsiflexion & 1.33 & 0.17 \\
\hline Hind-foot varus/valgus & 0.17 & 0.0 \\
\hline Foot progression angle & 0.25 & 0.33 \\
\hline Knee progression angle & 1.75 & 0.08 \\
\hline Peak knee extension & 0.92 & 0.25 \\
\hline Peak hip extension & 0.5 & 0.0 \\
\hline Pelvic obliquity at Mid-Stance & 0.92 & 0.58 \\
\hline Pelvic rotation at Mid-Stance & 0.42 & 0.17 \\
\hline Trunk Peak Sagittal Position & 1.0 & 0.83 \\
\hline Trunk maximum lateral shift & 1.33 & 1.1 \\
\hline Clearance & 0.33 & 0.0 \\
\hline Maximum ankle dorsiflexion & 1.17 & 0.33 \\
\hline Peak knee flexion & 1.0 & 0.25 \\
\hline Knee terminal swing position & 0.5 & 0.33 \\
\hline Peak hip flexion & 0.5 & 0.0 \\
\hline Total & $30.2 \pm 7.6$ & $11.7 \pm 7.4 *$ \\
\hline
\end{tabular}

Note: * - significant difference with the initial total value according to Mann-Whitney test $(\mathrm{p}<0.001)$
Table 4

Average Edinburgh scores in group of tibial detorsion

\begin{tabular}{|l|c|c|}
\hline Parameter & $\begin{array}{c}\text { Before } \\
\text { treatment }\end{array}$ & $\begin{array}{c}\text { Follow-up in } \\
1.5-2 \text { years }\end{array}$ \\
\hline Initial contact & 0.5 & 0.33 \\
\hline Heel lift & 0.67 & 0.67 \\
\hline Maximum ankle dorsiflexion & 0.67 & 0.0 \\
\hline Hind-foot varus/valgus & 0.67 & 0.0 \\
\hline Foot progression angle & 1.67 & 0.0 \\
\hline Knee progression angle & 0.67 & 0.17 \\
\hline Peak knee extension & 0.83 & 0.17 \\
\hline Peak hip extension & 0.83 & 0.33 \\
\hline Pelvic obliquity at Mid-Stance & 0.67 & 0.67 \\
\hline Pelvic rotation at Mid-Stance & 0.83 & 0.17 \\
\hline Trunk Peak Sagittal Position & 1.0 & 1.0 \\
\hline Trunk maximum lateral shift & 1.0 & 1.0 \\
\hline Clearance & 0.33 & 0.0 \\
\hline Maximum ankle dorsiflexion & 0.33 & 0.0 \\
\hline Peak knee flexion & 1.17 & 0.33 \\
\hline Knee terminal swing position & 0.83 & 0.33 \\
\hline Peak hip flexion & 0.67 & 0.0 \\
\hline Total & $26.7 \pm 14.3$ & $10.3 \pm 2.5^{*}$ \\
\hline
\end{tabular}

Note: $*$ - significant difference with the initial total value according to Mann-Whitney test $(\mathrm{p}<0.05)$

In five patients of group 2 before the operation, the changes in the parameters corresponded to true equinus gait (probable relapse of ankle joint contracture) in combination with the internal rotation of the lower extremities in the support phase. Several patients (seven patients) had internal rotation of the knee joint in combination with initial contact produced by the forefoot due to excessive bending of the knee joint at the terminal swing of the nonsupport phase, combined with subsequent late lift of the heel and insufficient extension of the knee joint in the support phase of the stride (Fig. 1).

This condition is explained by weakening of the triceps due to previous operations. After surgery at a long-term follow-up, the deviation from normal values decreased by almost three times. Correction of torsion of the femur significantly normalized the parameter of the knee orientation in the support phase of the gait cycle. Moreover, in the support phase, improvements (only for equinus gait cases) were recorded in the initial contact, heel lift, maximum dorsiflexion of the ankle, and pelvic rotation. Lengthening of the knee flexors enabled to improve peak extension of the knee joint in the support phase and terminal extension of the knee joint in the non-support phase in all patients (Fig. 2). In the non-support phase of the gait cycle, the parameters of clearance and maximum dorsiflexion of the foot 
improved. We also should note improvements in the trunk balance in the sagittal and frontal planes at

long-term as well as in pelvic obliquity in the support phase of the gait cycle.
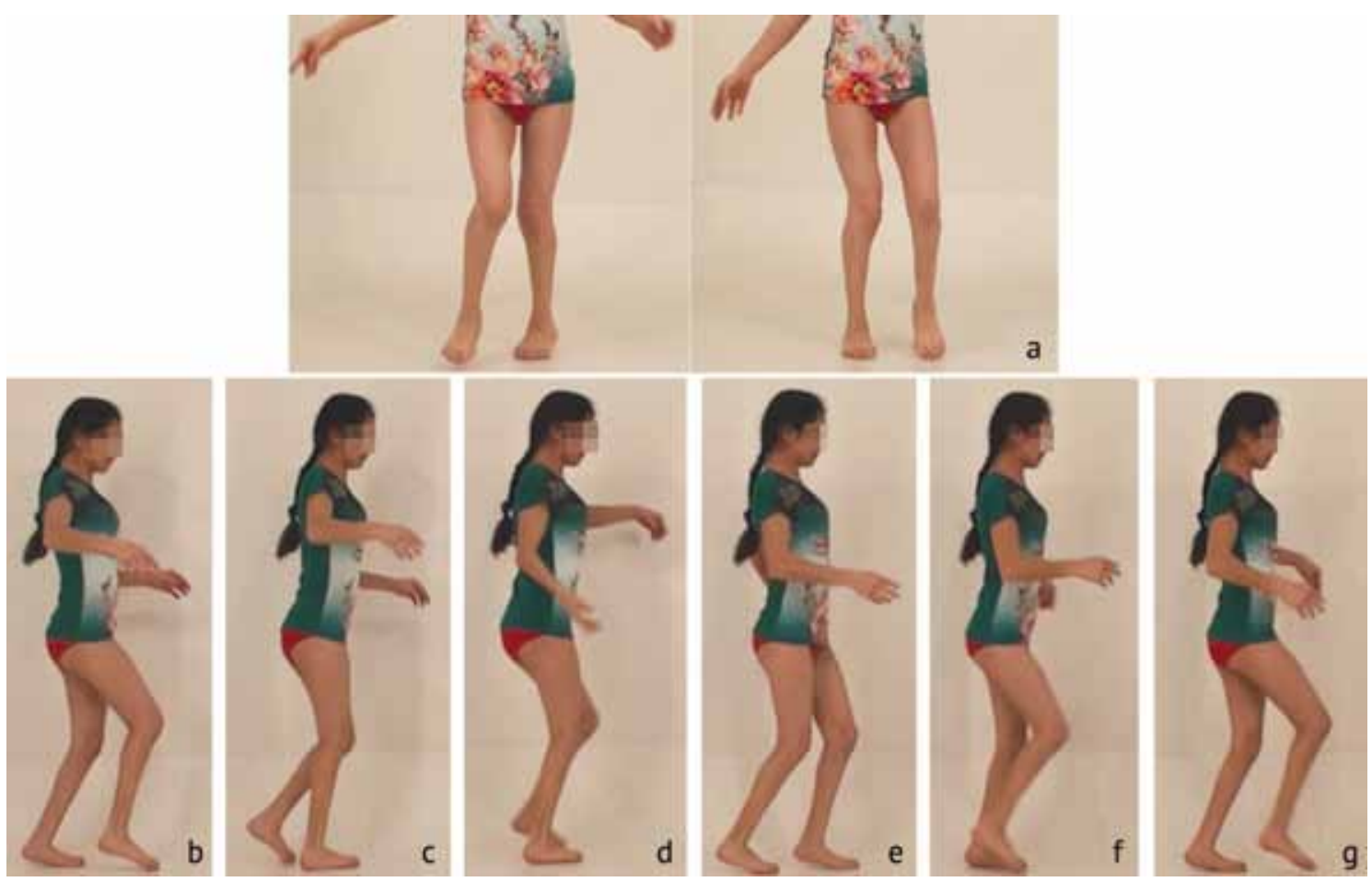

Fig. 1 Patient N., 18 years old, GMFCS level II, before surgery: $\boldsymbol{a}$ front view, mid stance of the support phase (on the left and right lower extremities), internal rotation, inclination of the pelvis towards the non-supporting limb; $\boldsymbol{b}$ initial contact of the right forefoot (beginning of the support phase for the right limb); $c$ separation of the left limb from the supporting surface, dorsiflexion of the right foot more than $15^{\circ} ; \boldsymbol{d}$ mid stance, bending of the right knee joint $25^{\circ} ; \boldsymbol{e}$ delay in lifting the heel of the right foot; $\boldsymbol{f}$ middle of the non-support phase for the right limb, normal maximum flexion of the knee joint; $\boldsymbol{g}$ terminal position of the right limb in the non-support phase, pathological excessive flexion of the knee joint

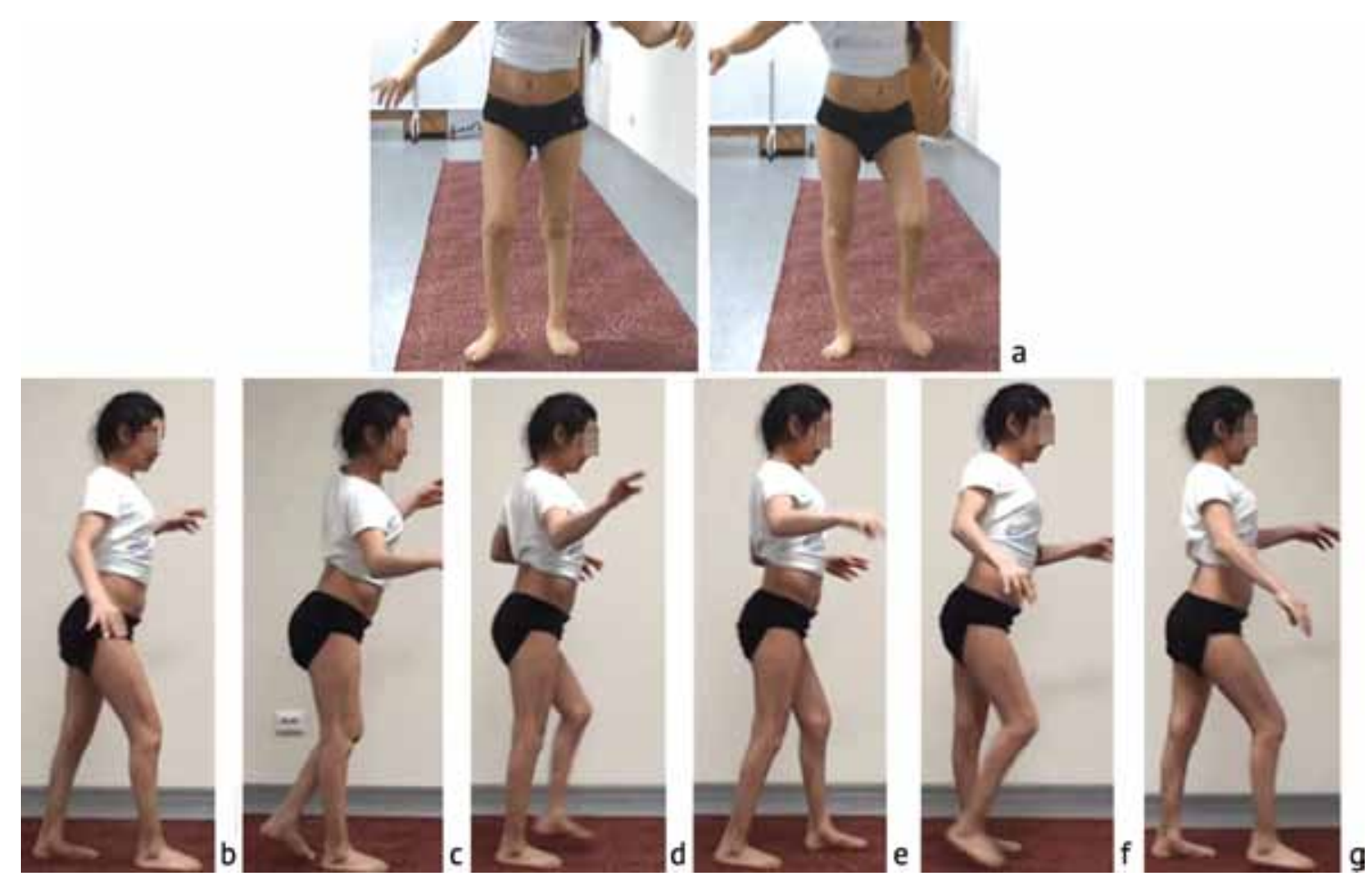

Fig. 2 Patient N., 18 years old, GMFCS level II, 1.5 year after surgery: $\boldsymbol{a}$ front view, mid stance of the support phase (on the left and right lower extremities), normal rotation, inclination of the pelvis towards the support limb for compensation; $\boldsymbol{b}$ full initial contact of the right foot (beginning of the support phase for the right limb); $c$ separation of the left limb from the supporting surface, dorsiflexion of the right foot $5^{\circ} ; \boldsymbol{d}$ mid stance of the support phase, full extension of the right knee joint; $\boldsymbol{e}$ delay in lifting the heel of the right foot; $f$ middle of the non-support phase (mid swing) for the right limb, normal maximum flexion of the knee joint; $\boldsymbol{g}$ terminal position of the right limb in the non-support phase, normal flexion of the knee joint 
By comparing the total scores between the groups before surgery according to the Mann-Whitney criterion, the differences were statistically significant in favor of the better results in patients of group 1, that is, the majority of which had not had earlier surgical interventions. We did not find statistically significant differences $(p=0.063)$ by evaluating the results in the long-term period; however, as before, the parameters were better in group 1 . In group 2 , the initial contact and heel lift remained changed.

There was no improvement in the trunk balance in either the first or second group in the long-term period: patients showed a significant trunk inclination forward and maintained frontal balance, significantly bending towards the supporting limb in the single support phase of the gait cycle.
In this group, the improvements mainly were foot position in the support phase and the improvement of the extension parameters of the knee joint in the support phase. The latter probably depended both on the lengthening of the flexors of the knee joint and on the elimination of the pathological orientation of the foot (elimination of lever arm dysfunction when a crouch gait begins to develop). However, the parameters of the trunk balance in the sagittal and frontal planes after the operations did not improve in both groups.

In general, multilevel interventions provided a significant improvement in the kinematic parameters of the gait in the long-term period in all three groups of patients.

\section{DISCUSSION}

In adolescents and adult patients with cerebral palsy, deterioration in functional and motor abilities, self-care, socialization, and quality of life is associated with the progression of orthopedic problems and the appearance of a pain caused by early degenerative arthritis [12-14].

In patients with a high motor activity corresponding to GMFCS level II, one of the orthopedic problems is torsion of the femur or lower leg bones. Detorsion osteotomies of the femurs are recommended as part of multilevel interventions in the event of a clinically significant internal rotational gait that causes daily difficulties in ambulation [1, 7].

Ounpuu S. et al. and Theologis T. pointed out the need to eliminate torsion deformities of the limbs in order to normalize the lever arm in the frontal and sagittal planes, which reduces energy consumption during motion $[15,16]$. By performing correction, anatomical parameters in adults correlate with the grade of gait disorder, which facilitates the calculation and technical performance of the operation [1, 17]. We should note that in multilevel interventions, it is more expedient to perform corrective osteotomy in the distal part of the affected segment in order to reduce blood loss and operation time, as well as technical convenience for the surgical team during a multilevel surgical intervention on the femur and underlying segments [4].

Correction of internal torsion of the tibias facilitates patients' walking while correction of external torsion of this segment prevents crouch gait as it eliminates dysfunction of lever arms [2, 18-20]. Finally, multilevel interventions that include correction of torsion improve the overall motor activity and social integration of patients [3, 21].

We observed a stable positive effect of improved gait parameters in our group of patients that were studied using the Edinburgh visual gait score. First of all it refers to the relationship in the knee and ankle joints as well as feet relative the patient's motion vector by walking. Other improvements were changes in the parameters of motion in the sagittal plane due to simultaneous elimination of contractures in the lower limb joints.

The literature sources state that the rehabilitation period after surgical interventions in adolescents and adults with cerebral palsy runs longer and does not always end in the improvement of motion abilities that were lost due to orthopaedic complications in CP [1]. We suppose that the latter is one of the reasons of the condition after correction of orthopaedic disorders in the lower limbs but the improvement of trunk position and balance might be expected after continuous rehabilitation and observation of patients during the long term of more than two years. The same general improvement of gait and knee and ankle joint kinematics and lack of improvements in the gait parameters that characterize the trunk balance by walking was observed by some authors that performed multilevel interventions that also included detorsion osteotomies of femurs. 
Our study, in addition to the importance and validity of torsion correction, shows a negative impact of the operations performed at an early age (under 5 years of age) which include percutaneous fibromyotomy or open lengthening of the Achilles tendon. In adolescents and adult patients with a potentially high level of motor capabilities (GMFCS level II) who underwent those interventions, we observed pronounced disturbances in the parameters of the initial contact of the foot with the surface, excessive dorsiflexion of the foot and excessive flexion in the knee joint in the single-leg support phase of the gait cycle. Another sign of iatrogenic weakening of the leg triceps was a late heel lift.
Thus, a preoperative analysis of gait parameters in this series of patients confirmed that early operations such as fibromyotomy or open lengthening of the Achilles tendon have an unfavorable longterm effect which is persistent weakening of the affected muscles. According to the literature, such early unreasonable interventions performed before muscle retraction has developed result in functional insufficiency of the triceps of the lower leg, loss of strength of the eccentric contraction of the soleus muscle in the support phase at the moment of kinetic energy absorption, which is accompanied by premature flexion in the knee joint and the risk of failure of its extensor apparatus [22, 23].

\section{CONCLUSION}

Correction of clinically significant torsion in the lower limbs (torsion value of 20 degrees or more according to CT data) in adult patients with cerebral palsy as part of multilevel single-event interventions results in improvement of gait parameters and the overall total of the parameters. The most significant improvements were the orientation of the knee and ankle joints in the horizontal plane, as well as movements in these joints. During the follow-up period of 1.5 to 2 years after the operation, there was no improvement in the parameters of the trunk balance by walking. Patients who underwent surgical interventions in early childhood had worse walking parameters before surgery than patients not previously operated. We believe that in our patient sample the crouch gait did not develop only due to high motor activity of patients and due to relatively mild neurological disorders. The total of gait parameters was statistically significantly higher in the group of patients who did not undergo soft tissue surgery in childhood at all than in the patients who had early interventions.

Publication ethics: Patients gave voluntary informed consent to the publication.

Conflict of interest: none

Source of funding: not announced.

\section{REFERENCES}

1. Putz C., Wolf S.I., Geisbüsch A., Niklasch M., Döderlein L., Dreher T. Femoral derotation osteotomy in adults with cerebral palsy. Gait Posture, 2016, vol. 49, pp. 290-296. DOI: 10.1016/j.gaitpost.2016.06.034.

2. Gannotti M.E., Gorton G.E. 3rd, Nahorniak M.T., Masso P.D. Walking abilities of young adults with cerebral palsy: changes after multilevel surgery and adolescence. Gait Posture, 2010, vol. 32, no. 1, pp. 46-52. DOI: 10.1016/j.gaitpost.2010.03.002.

3. Ławniczak D., Jóźwiak M., Manikowska F. Assessment of absolute knee joint linear and angular velocity in patients with spastic cerebral palsy after operative treatment of lever arm dysfunction deformities - prospective study. Chir. Narzadow Ruchu Ortop. Pol., 2010, vol. 75, no. 2, pp. 92-97.

4. Pirpiris M., Trivett A., Baker R., Rodda J., Nattrass G.R., Graham H.K. Femoral derotation osteotomy in spastic diplegia. Proximal or distal ? J. Bone Joint Surg. Br., 2003, vol. 85, no. 2, pp. 265-272.

5. Popkov D.A., Zmanovskaia V.A., Gubina E.B., Leonchuk S.S., Butorina M.N., Pavlova O.L. Rezultaty mnogourovnevykh odnomomentnykh ortopedicheskikh operatsii i rannei reabilitatsii v komplekse s botulinoterapiei u patsientov so spasticheskimi formami tserebralnogo paralicha [Results of multilevel single-event orthopedic suargeries and early rehabilitation in combination with botulinum therapy in patients with cerebral palsy spastic forms]. Zhurnal Nevrologii i psikhiatrii im. S.S. Korsakova, 2015 , vol. 115, no. 4, pp. 41-48. (in Russian) DOI: 10.17116/jnevro20151154141-48.

6. Yalçin S., Kocaoğlu B., Berker N., Erol B. Surgical management of orthopedic problems in adult patients with cerebral palsy. Acta Orthop. Traumatol. Turc., 2005, vol. 39, no. 3, pp. 231-236.

7. Gatamov O.I., Chibirov G.M., Borzunov D.Y., Popkov D.A. Khirurgicheskoe ortopedicheskoe lechenie vzroslykh patsientov s DTsP: obzor literatury i predvaritelnyi analiz sobstvennykh rezultatov [Surgical orthopaedic management of cerebral palsy in adults: literature review and preliminary analysis of our treatment experience]. Genij Ortopedii, 2018, vol. 24, no. 4, pp. 538-547. (in Russian) DOI: 10.18019/1028-4427-2018-24-4-538-547.

8. Putz C., Döderlein L., Mertens E.M., Wolf S.I., Gantz S., Braatz F., Dreher T. Multilevel surgery in adults with cerebral palsy. Bone Joint J., 2016, vol. 98-B, no. 2, pp. 282-288. DOI: 10.1302/0301-620X.98B2.36122.

9. Benner J.L., Hilberink S.R., Veenis T., Stam H.J., Van der Slot W.M., Roebroeck M.E. Long-Term Deterioration of Perceived Health and Functioning in Adults With Cerebral Palsy. Arch. Phys. Med. Rehabil., 2017, vol. 98, no. 11, pp. 2196-2205. DOI: 10.1016/j.apmr.2017.03.013. 
10.Shishov S.V., Ivshin V.G. Minimalno invazivnye operatsii na myshtsakh u detei s DTsP. Opyt piatiletnego primeneniia [Minimally invasive surgery of muscles in children with cerebral palsy. The experience of five-year use]. Vestnik Novykh Meditsinskikh Tekhnologii (Electronic Edition), 2016, no. 2, pp. 137-141. (in Russian) DOI: 10.12737/20085.

11.Novacheck T.F., Stout J.L., Tervo R. Reliability and validity of the Gillette Functional Assessment Questionnaire as an outcome measure in children with walking disabilities. J. Pediatr. Orthop., 2000, vol. 20, no. 1, pp. 75-81.

12.Ando N., Ueda S. Functional deterioration in adults with cerebral palsy. Clin. Rehabil., 2000, vol. 14, no. 3, pp. $300-306$.

13.Baer H.R., Thomas S.P., Pan Z., Tagawa A., Carollo J.J., Heyn P.C. Self-reported physical function is associated with walking speed in adults with cerebral palsy. J. Pediatr. Rehabil. Med., 2019, vol. 12, no. 2, pp. 181-188. DOI: 10.3233/PRM-180585.

14.O'Connell N.E., Smith K.J., Peterson M.D., Ryan N., Liverani S., Anokye N., Victor C., Ryan J.M. Incidence of osteoarthritis, osteoporosis and inflammatory musculoskeletal diseases in adults with cerebral palsy: A population-based cohort study. Bone, 2019, vol. 125, pp. 30-35. DOI: 10.1016/j.bone.2019.05.007.

15.Ounpuu S., DeLuca P., Davis R., Romness M. Long-term effects of femoral derotation osteotomies: an evaluation using threedimensional gait analysis. J. Pediatr. Orthop., 2002, vol. 22, no. 2, pp. 139-145.

16.Theologis T. Lever arm dysfunction in cerebral palsy gait. J. Child. Orthop., 2013, vol. 7, no. 5, pp. 379-382. DOI: 10.1007/s11832013-0510-y.

17.Radler C., Kranzl A., Manner H.M., Höglinger M., Ganger R., Grill F. Torsional profile versus gait analysis: consistency between the anatomic torsion and the resulting gait pattern in patients with rotational malalignment of the lower extremity. Gait Posture, 2010, vol. 32, no. 3, pp. 405-410. DOI: 10.1016/j.gaitpost.2010.06.019.

18.Graham H.K., Rosenbaum P., Paneth N., Dan B., Lin J.P., Damiano D.L., Becher J.G., Gaebler-Spira D., Colver A., Reddihough D.S., Crompton K.E., Lieber R.L. Cerebral palsy. Nat. Rev. Dis. Primers, 2016, vol. 2, pp. 15082. DOI: 10.1038/nrdp.2015.82.

19.Thompson R.M., Ihnow S. , Dias L., Swaroop V. Tibial derotational osteotomies in two neuromuscular populations: comparing cerebral palsy with myelomeningocele. J. Child. Orthop., 2017, vol. 11, no. 4, pp. 243-248. DOI: 10.1302/1863-2548.11.170037.

20.Stefko R.M., De Swart R.J., Dodgin D.A., Wyatt M.P., Kaufman K.R., Sutherland D.H., Chambers H.G. Kinematic and kinetic analysis of distal derotational osteotomy of the leg in children with cerebral palsy. J. Pediatr. Orthop., 1998, vol. 18, no. 1, pp. 81-87.

21.Lehtonen K., Mäenpää H., Piirainen A. Does single-event multilevel surgery enhance physical functioning in the real-life environment in children and adolescents with cerebral palsy (CP)?: patient perceptions five years after surgery. Gait Posture, 2015, vol. 41, no. 2, pp. 448-453. DOI: 10.1016/j.gaitpost.2014.11.005.

22.Borton D.C., Walker K., Pirpiris M., Nattrass G.R., Graham H.K. Isolated calf lengthening in cerebral palsy. Outcome analysis of risk factors. J. Bone Joint Surg. Br., 2001, vol. 83, no. 3, pp. 364-370.

23.Miller F. Cerebral Palsy. $1^{\text {st }}$ Ed. New York, Springer-Verlag, 2005. DOI: 10.1007/b138647.

Received: 06.09.2019

\section{Information about the authors:}

1.Orhan I. Gatamov, M.D.,

Russian Ilizarov Scientific Centre for Restorative Traumatology and Orthopaedics, Kurgan, Russian Federation,

2. Georgy M. Chibirov, M.D., Ph.D.,

Russian Ilizarov Scientific Centre for Restorative Traumatology and Orthopaedics, Kurgan, Russian Federation, Email: georgii_chibirov@mail.ru

3. Dmitry Yu. Borzunov, M.D., Ph.D.,

Russian Ilizarov Scientific Center for Restorative Traumatology and Orthopaedics, Kurgan, Russian Federation, Tyumen state medical university, Tyumen, Russian Federation,

Email: borzunov@bk.ru

4. Tamara I. Dolganova, M.D., Ph.D.,

Russian Ilizarov Scientific Center for Restorative Traumatology and Orthopaedics, Kurgan, Russian Federation, Email: rjik532007@rambler.ru

5. Dmitrii V. Dolganov, Ph.D. of Biological Sciences,

Russian Ilizarov Scientific Center for Restorative Traumatology and Orthopaedics, Kurgan, Russian Federation, Email: Paradigma-DV@rambler.ru

6. Dmitry A. Popkov, M.D., Ph.D., Professor of RAS, correspondent member French Academy of Medical Sciences Russian Ilizarov Scientific Centre for Restorative Traumatology and Orthopaedics, Kurgan, Russian Federation, Email: dpopkov@mail.ru 